\title{
O que os mestrados profissionais têm a nos ensinar: análise de uma proposta
}

\author{
What a professional master of science may teach us: a proposal analysis
}

Qué nos pueden enseñar los masters profesionales: análisis de una propuesta

\author{
Denise Ivana de Paula Albuquerque ${ }^{1}$; Maria Candida Soares Del Massoº \\ ANDREIA DE CARVAlHo LOPES FUJIHARA ${ }^{3}$
}

Universidade Estadual Paulista “Júlio de Mesquita Filho”, UNESP, Presidente Prudente-SP, Brasil

\begin{abstract}
RESUMO
Neste estudo analisamos as contribuições dos mestrados profissionais (MP) para a formação dos professores apresentando a proposta do Programa de Mestrado Profissional em Educação Física em Rede Nacional (ProEF). Iniciamos com breve análise do Sistema de Pós-Graduação Stricto Sensu no Brasil, destacando o marco institucional dado pelo Parecer n 977/1965, conhecido como Parecer Sucupira. Embora datado de 1965, na década de 1930, o Decreto $n^{\circ}$ 19.851/1931, que criou o Estatuto das Universidades Brasileiras, é considerado o início da pós-graduação no país. O MP inicia com a Portaria $n^{\circ} 7 / 2009$, atualizada pela Portaria $n^{\circ} 17 / 2009$. Em 2011 é criado o Programa de Mestrado Profissional para Professores da Educação Básica (ProEB). O ProEF, vinculado ao ProEB, inicia em 2018 e, em 2020, finaliza a $1^{a}$ turma com 169 Mestres em Educação Física Escolar atuando na Educação Básica que utilizaram o campo de trabalho do professor, da escola e da sua comunidade para os estudos, pesquisas e intervenções dos MP.
\end{abstract} Palavras-chave: Educação Física Escolar. Pós-Graduação em Educação Física. Mestrado Profissional. ProEF. ProEB.

\begin{abstract}
This research has performed an analysis of the Professional Master of Science (PM) to enhance the development of teachers establishing a proposal of the Physical Education Professional Master of Science in Brazil (ProEF). We started out with a brief analysis of the Stricto Sensu Post-graduation in Brazil outstanding the institutional point referring to Institutional Act 977/1965, known as Sucupira Report. Although from 1965, the Institutional Act 19.851/1931, which created the Brazilian Universities decree is considered the beginning of Post-graduation in the country. The PM begins with the Institutional Act 7/2009, updated by Institutional Act 17/2009. In 2011, the Professional Master of Science Program for Basic Education Teachers (ProEB) is created. The ProEF, bound to ProEB, starts out in 2018 and in 2020 comes up with the first group with 169 Professional Master of Science in Physical Education working on basic education who made use of the work field of the teacher, school and its community for the studies, research and intervention of the Professional Master of Science.
\end{abstract}

Keywords: Scholar Physical Education. Physical Education. Physical Education Professional Master of Science. ProEF. ProEB.

\section{RESUMEN}

Este estudio analizó las contribuciones de las maestrías profesionales (MP) a la formación de docentes, presentando la propuesta del Programa de Maestría Profesional en Educación Física en la Red Nacional (ProEF). Comenzamos con un breve análisis del Sistema de Posgrado Stricto Sensu en Brasil, destacando el marco institucional dado por el Parecer No. 977/1965, conocido como Parecer Sucupira. Aunque data de 1965, en la década de 1930 el Decreto 19.851 / 1931, que creó el Estatuto Universitario Brasileño, se considera el inicio de los estudios de posgrado en el país. El MP comienza con la Ordenanza No. 7/2009, actualizada por la Ordenanza No. 17/2009. En 2011 se crea el Programa de Maestría Profesional para Docentes de Educación Básica (ProEB). El ProEF, vinculado al ProEB, comienza en 2018 y 2020 y finaliza la 1a promoción con 169 Maestros en Educación Física Escolar trabajando en Educación Básica y que utilizaron el campo de trabajo del docente, la escuela y su comunidad para los estudios, investigaciones e intervención de los MP.

Palabras clave: Educación Física Escolar. Postgrado en Educación Física. Máster profesional. ProEF. ProEB.

\footnotetext{
${ }^{1}$ Professora do Departamento de Educação Física (Faculdade de Ciências e Tecnologia, UNESP Presidente Prudente), Coordenadora Nacional e Docente do Programa de Mestrado Profissional em Educacional Física em Rede Nacional (ProEF/UNESP Presidente Prudente). E-mail: denise.albuquerque@unesp.br. ORCID: http://orcid.org/0000-00025673-5650.

${ }^{2}$ Professora do Instituto de Educação e Pesquisa em Práticas Pedagógicas (IEP3/UNESP Presidente Prudente), ViceCoordenadora Nacional e docente do Programa de Mestrado Profissional em Educacional Física em Rede Nacional (ProEF/UNESP Presidente Prudente). E-mail: del.masso@ unesp.br. ORCID: http://orcid.org/0000-0003-2573-437X. ${ }^{3}$ Assessora Pedagógica do Programa de Mestrado Profissional em Educação Física em Rede Nacional (ProEF/UNESP Presidente Prudente). E-mail: andreia.lopes@ unesp.br. ORCID: http://orcid.org/0000-0003-2809-4128.
} 


\section{INTRODUÇÃO}

A efetiva docência ao longo da história tem demonstrado um complexo processo devido a diferentes fatores, como: o contexto educacional, o social, o econômico e o político, que podem ser transformados pelo desenvolvimento científico e tecnológico.

Com isso, percebemos movimento constante no trabalho docente, que podemos considerar como importante oportunidade de formação para ação e reflexão desses profissionais. O princípio da ação-reflexão-ação sugere que o processo formativo deve proporcionar um conjunto de conhecimentos, experiências e aptidões necessárias à formação de um profissional reflexivo, tendo como base um conjunto de competências instrumentais, interpessoais e sistêmicas, conforme argumenta Schön (2000). Isto é, o campo de trabalho do professor, a escola e toda sua comunidade envolvida, são o berço do desenvolvimento para os estudos e pesquisas dos mestrados profissionais, já que o grande objeto de pesquisa é a prática pedagógica interventiva no cotidiano escolar que possa gerar produtos que alcancem todos os professores e estudantes.

Nesse contexto, o mestrado profissional começa a ter visibilidade no Brasil a partir da oficialização pela Coordenação de Aperfeiçoamento de Pessoal de Nível Superior (Capes) da Portaria Normativa $\mathrm{n}^{\circ}$ 07, de 22 de junho de 2009 (BRASIL, 2009a), que dispõe sobre essa modalidade de curso no âmbito da Pós-Graduação stricto sensu no Brasil. Nesse mesmo ano, visando corrigir distorções, essa Portaria foi atualizada pela Portaria Normativa $\mathrm{n}^{\text {o }}$ 17, de 28 de dezembro de 2009 (BRASIL, 2009b), abordando, principalmente, o prazo de conclusão dos cursos e a igualdade de direitos dos mestres acadêmicos e dos mestres profissionais. Mais recentemente, foi exarada a Portaria $n^{\circ}$ 389, de 23 de março de 2017 (BRASIL, 2017), do Ministério da Educação, que dispõe sobre o mestrado e doutorado profissional no âmbito da pósgraduação stricto sensu.

Ao pontuar essas legislações e revisitando Waters (2006) quando este, ao se referir às publicações científicas decorrentes de diferentes estudos e pesquisas, mais pontualmente decorrentes dos programas de pós-graduação, o autor argumenta que, para os órgãos científicos de avaliação o número de livros publicados é mais importante que sua utilidade para a ciência. Destaca que se publica de tudo para ser produtivo, mesmo que isso signifique trabalhos menos qualificados e sem leitores e vive-se a ditadura da contagem da produção. Se critérios de conteúdo, antes da aceitação e publicação, não forem revistos, fica ameaçada a esperança de preservação da pujança da pesquisa acadêmica e de sua correspondente produção editorial, finaliza Waters (2006).

Com certeza, quando Waters fez esses apontamentos, já estava em trâmite a possibilidade de se efetivar o mestrado profissional no Brasil, dando ênfase a um novo modelo de produção acadêmica que fizesse sentido aos profissionais que desejassem se atualizar para a melhoria da sua prática profissional, não necessariamente para a sua formação para a docência e pesquisa, o que é prioritário aos programas de pósgraduação acadêmicos.

A reflexão de Waters (2006), publicada anterior às legislações brasileiras, para dar legalidade ao mestrado profissional, nos remete à análise da importância desta modalidade de formação no âmbito da pós-graduação, e hoje abrangendo também o doutorado profissional sugere a analogia do que representa o resultado dessas ações na prática cotidiana do país, ou seja, o que se pretende produzir e publicar? Qual a novidade? Para quem? Onde será utilizado?

Tomando-se por base esses questionamentos, somos remetidos a outras reflexões necessárias de serem analisadas, quais sejam: a diferença entre os mestrados profissionais e acadêmicos na legislação brasileira e o que se produz na conclusão 
desses cursos, aspectos importantes para a produção científica e para sua aplicabilidade na prática profissional brasileira.

\title{
Mestrados e Doutorados Profissionais e Programa de Mestrado Profissional para Professores da EduCaÇão Básica - ProEB
}

Antes de analisarmos brevemente alguns aspectos das legislações que envolvem o Mestrado e o Doutorado Acadêmico, é importante conhecermos o início da PósGraduação no Brasil. Seu histórico é interessante e, se analisarmos, usando certa analogia, seremos remetidos, de algum modo, ao atual preceito do Mestrado Profissional.

Conforme afirmam Almeida Junior et al. (2005 apud SANTOS; HORTALE; AROUCA, 2012, p. 27) o "[...] marco da institucionalização do sistema de pósgraduação stricto sensu se deu pelo Parecer $n^{\circ}$ 977, datado de 03 de dezembro de 1965, também conhecido como Parecer Sucupira, uma homenagem ao seu relator Newton Sucupira". Embora oficialmente seja datado de 1965, na década de 1930, "Francisco Campos, autor do Decreto $\mathrm{n}^{\mathrm{o}}$ 19.851, de 11 de abril de 1931, que criou o Estatuto das Universidades Brasileiras, mesmo não empregando o termo, é considerado, pelo próprio Sucupira, o pioneiro da pós-graduação no Brasil" (SUCUPIRA, 1980 apud SANTOS; HORTALE; AROUCA, 2012, p. 27). Campos destinava os cursos de bacharelado em direito à formação puramente profissional, ao passo que os cursos de doutorado visavam à formação de professores em direito. Esse é um aspecto interessante e parece vir ao encontro da proposta atual do mestrado profissional ao referir-se puramente à formação profissional, mesmo que no âmbito da graduação e apontando como pós-graduação apenas o doutorado em direito.

A pós-graduação avançou no país, após vários estudos,

\begin{abstract}
Sem deixar de reconhecer o papel da universidade em também promover a profissionalização, o desenvolvimento científico e o treinamento de pesquisadores, Sucupira deixa transparecer, no documento, a esperança de um conhecimento interessado e comprometido tanto com as questões sociais quanto com a instauração da pós-graduação. Contido, para ele, o cumprimento das novas funções atribuídas à pós-graduação demandava uma reestruturação, não somente das finalidades do ensino superior, mas sua organização, especialmente dos níveis necessários de formação e do tipo de cursos a eles correspondentes. Preocupado, portanto, em estabelecer uma distinção entre a formação do "profissional comum, a do cientista e a do tecnólogo", ele defendeu três motivos para a instauração imediata do 'novo' modelo de pós-graduação no país: a qualificação de professores para o ensino superior, o desenvolvimento da pesquisa científica e o treinamento de técnicos e trabalhadores do mais alto padrão. Sobre este terceiro e último objetivo repousa o argumento, com crescente adesão de algumas áreas do conhecimento, de que o mestrado profissional fora recomendado no Parecer 977/65. Dessa forma, a Portaria Capes $\mathrm{n}^{0} 47$, que o torna 'oficial', fez somente atualizar um projeto que até então não ultrapassava as fronteiras da recomendação (SANTOS; HORTALE; AROUCA, 2012, p. 28-29).
\end{abstract}

Conforme registrado por Santos, Hortale e Arouca (2012), a Portaria $n^{\circ}$ 47/1995 (BRASIL, 1995) resolve:

Determinar a implantação na Capes de procedimentos apropriados à recomendação, acompanhamento e avaliação de cursos de mestrado dirigidos à formação profissional, nos termos do referido documento, e do Parecer que o fundamentou, destacando-se que, para assegurar níveis de qualidade 
comparáveis aos vigentes no sistema de pós-graduação e consistentes com a especificidade dos cursos, ficam estabelecidos os requisitos e condicionantes (BRASIL, 1995, p. 147).

Interessante destacar que nos itens 3 e 5 dos requisitos e condicionantes da referida Portaria $\mathrm{n}^{\mathrm{o}} 47$ fica realmente clara na proposta, já em 1995, aspectos voltados ao mestrado profissional conforme apresentamos, a seguir, com ênfase nos textos grifados:

3. O curso deverá articular as atividades de ensino com as aplicações de pesquisas, em termos coerentes com seu objetivo, de forma diferenciada e flexível. A existência de pesquisa de boa qualidade na instituição e de projetos em parceria com o setor produtivo, bem como a oferta de atividades de extensão, são requisitos essenciais ao credenciamento institucional para oferta deste tipo de curso.

5. O estudante deve apresentar trabalho final que demonstre domínio do objeto de estudo e capacidade de expressar-se lucidamente sobre ele. De acordo com a natureza da área e com a proposta do curso, esse trabalho poderá tomar formas como, entre outras, dissertação, projeto, análise de casos, performance, produção artística, desenvolvimento de instrumentos, equipamentos e protótipos (BRASIL, 1995, p. 147, grifos nossos).

Embora, ainda com certo desconhecimento e possíveis resistências por parte da comunidade acadêmica, o Mestrado Profissional é uma realidade concretizada no Brasil. Conforme apresentado na Portaria Normativa $n^{\circ} 7$, de 22 de junho de 2009, do Ministério da Educação, que dispõe sobre o mestrado profissional no âmbito da Fundação Coordenação de Aperfeiçoamento de Pessoal de Nível Superior - CAPES, os argumentos iniciais para a normatização desses Mestrados foram:

CONSIDERANDO a necessidade de identificar potencialidades para atuação local, regional, nacional e internacional por órgãos públicos e privados, empresas, cooperativas e organizações não-governamentais, individual ou coletivamente organizadas;

CONSIDERANDO a necessidade de atender, particularmente nas áreas mais diretamente vinculadas ao mundo do trabalho e ao sistema produtivo, a demanda de profissionais altamente qualificados;

CONSIDERANDO as possibilidades a serem exploradas em áreas de demanda latente por formação de recursos humanos em cursos de pósgraduação stricto sensu com vistas ao desenvolvimento socioeconômico e cultural do País:

CONSIDERANDO a necessidade de capacitação e treinamento de pesquisadores e profissionais destinados a aumentar o potencial interno de geração, difusão e utilização de conhecimentos científicos no processo produtivo de bens e serviços em consonância com a política industrial brasileira;

CONSIDERANDO a natureza e especificidade do conhecimento científico e tecnológico a ser produzido e reproduzido;

CONSIDERANDO a relevância social, científica e tecnológica dos processos de formação profissional avançada, bem como o necessário estreitamento das relações entre as universidades e o setor produtivo; e, finalmente,

CONSIDERANDO o disposto na Lei $\mathrm{n}^{\circ}$ 9.394, de 20 de dezembro de 1996, as deliberações do Conselho Técnico-Científico da Educação Superior CTC-ES e as deliberações do Conselho Superior da CAPES,

RESOLVE:

Art. $1^{\circ}$ A Fundação Coordenação de Aperfeiçoamento de Pessoal de Nível Superior - CAPES regulará a oferta de programas de mestrado profissional mediante chamadas públicas e avaliará os cursos oferecidos, na forma desta Portaria e de sua regulamentação própria (BRASIL, 2009a, p. 2). 
O Mestrado Profissional já há tempos era uma necessidade latente no país, considerando a constante busca por qualificações e capacitações de profissionais que estavam inseridos no mercado de trabalho, não necessariamente na universidade, os quais desejavam atualizar-se para a melhoria do seu cotidiano profissional em âmbito de formação pós-graduada stricto sensu.

Nessa perspectiva, os objetivos do Mestrado Profissional, conforme incisos do Artigo $4^{\circ}$ da referida portaria foram:

I - capacitar profissionais qualificados para o exercício da prática profissional avançada e transformadora de procedimentos, visando atender demandas sociais, organizacionais ou profissionais e do mercado de trabalho;

II - transferir conhecimento para a sociedade, atendendo demandas específicas e de arranjos produtivos com vistas ao desenvolvimento nacional, regional ou local;

III - promover a articulação integrada da formação profissional com entidades demandantes de naturezas diversas, visando melhorar a eficácia e a eficiência das organizações públicas e privadas por meio da solução de problemas e geração e aplicação de processos de inovação apropriados;

IV - contribuir para agregar competitividade e aumentar a produtividade em empresas, organizações públicas e privadas.

Parágrafo único. No caso da área da saúde, qualificam-se para o oferecimento do mestrado profissional os programas de residência médica ou multiprofissional devidamente credenciados e que atendam aos requisitos estabelecidos em edital específico (BRASIL, 2009a, p. 2).

Fica evidente pelos seus objetivos a abrangência dessas propostas, as quais poderão ser demandas por "[...] universidades, instituições de ensino e centros de pesquisa, públicos e privados, inclusive em forma de consórcio, atendendo necessária e obrigatoriamente aos requisitos de qualidade fixados e, em particular, demonstrando experiências na prática do ensino e da pesquisa aplicada" (BRASIL, 2009a, p. 2), conforme pontuado no Artigo $5^{\circ}$ desta Portaria. No Parágrafo Único da Portaria, a ênfase é dada aos:

[...] princípios de aplicabilidade técnica, flexibilidade operacional e organicidade do conhecimento técnico-científico, visando o treinamento de pessoal pela exposição dos alunos aos processos de utilização aplicada dos conhecimentos e o exercício da inovação, visando a valorização da experiência profissional (BRASIL, 2009a, p. 2).

Com a apresentação das diferentes propostas frente à atual legislação e em consonância aos demais documentos acadêmicos para os programas de pós-graduação stricto sensu, houve a necessidade de algumas correções na regulamentação dos cursos e da oferta de mestrado profissional. A nova redação dada pela Portaria Normativa $\mathrm{n}^{\circ}$ 17, de 28 de dezembro de 2009 (BRASIL, 2009b), com as devidas correções, abordou, principalmente, o prazo de conclusão dos cursos e a igualdade de direitos dos mestres acadêmicos e profissionais. Assim, conforme previsto no Sistema Nacional de PósGraduação, os preceitos para o mestrado acadêmico e profissional, destacamos que ambos seguem as mesmas diretivas, assim os títulos são iguais e, consequentemente, os direitos adquiridos com a conclusão do curso. Amaral (BRASIL, 2009c) enfatiza em seu texto que:

[...] o principal objetivo do mestrado profissional é formar recursos humanos para atuar em setores não acadêmicos, transferir conhecimentos à sociedade, atender demandas específicas e arranjos produtivos para o desenvolvimento nacional, regional e local. Além disso, contribuir para ampliar a 
competitividade e a produtividade de empresas, organizações públicas e particulares (BRASIL, 2009c).

Com o crescimento das propostas de Mestrado Profissional e o interesse pela continuidade dos estudos, é exarada a Portaria $n^{\circ} 389$, de 23 de março de 2017 (BRASIL, 2017), que dispões sobre o mestrado e doutorado profissional no âmbito da Pós-Graduação Stricto Sensu considerando a "[...] relevância social, científica e tecnológica dos processos de formação profissional avançada, bem como o necessário estreitamento das relações entre universidades e o setor produtivo" (BRASIL, 2017, p. $61)$.

Analisando este documento mais recente da Capes, Portaria $\mathrm{n}^{\circ} 389$ (BRASIL, 2017) e as propostas exaradas mediante a Portaria $n^{\circ} 17 / 2009$ (BRASIL, 2009b) e a Portaria no 47/1995 (BRASIL, 1995), observamos várias semelhanças que sugerem que os documentos iniciais foram revistos e atualizados para o atual momento acadêmicoprofissional no país, particularmente no que se refere ao mestrado e doutorado profissional. Assim, são objetivos do mestrado e doutorado profissional, conforme Artigo $2^{\circ}$ :

I - capacitar profissionais qualificados para o exercício da prática profissional avançada e transformadora de procedimentos, visando atender demandas sociais, organizacionais ou profissionais e do mercado de trabalho;

II - transferir conhecimento para a sociedade, atendendo demandas específicas e de arranjos produtivos com vistas ao desenvolvimento nacional, regional ou local;

III - promover a articulação integrada da formação profissional com entidades demandantes de naturezas diversas, visando melhorar a eficácia e a eficiência das organizações públicas e privadas por meio da solução de problemas e geração e aplicação de processos de inovação apropriados; e

IV - contribuir para agregar competitividade e aumentar a produtividade em empresas, organizações públicas e privadas (BRASIL, 2017, p. 61).

Na redação desta nova Portaria de 2017, em seu Artigo 2 $2^{\circ}$, foi excluído o Parágrafo Único do Artigo $4^{\circ}$ da Portaria 17/2009 (BRASIL, 2009b, p. 21) que abordava a área de saúde informando que "[...] qualificam-se para o oferecimento de mestrado profissional os programas de residência médica e multiprofissionais devidamente credenciados e que atendam aos requisitos estabelecidos em edital específico".

Somado ao avanço que o Sistema de Pós-Graduação Stricto Sensu obteve no país com a implantação do mestrado e doutorado profissional, a Portaria $n^{\circ}$ 275/2018 (BRASIL, 2018) que dispõe sobre os programas de pós-graduação stricto sensu na modalidade a distância, abre-se novo leque de opções para os cursos de mestrado e doutorado tanto acadêmico quanto profissional podendo ser presencial quanto a distância. Importante destacarmos no Capítulo I - Das Disposições Gerais, da Portaria $n^{\circ} 275$ :

Art. $2^{\circ}$ Um programa de pós-graduação é composto por no máximo dois cursos, sendo um em nível de mestrado e outro em nível de doutorado, podendo serem ofertados nas modalidades presencial ou a distância de acordo com as normas vigentes.

Art. $3^{\circ}$ Os cursos de pós-graduação na modalidade a distância seguirão as normas vigentes aplicáveis a todos os programas de pós-graduação stricto sensu, atendendo também às especificidades desta Portaria e de outros regulamentos próprios. 
Art. $4^{\circ}$ Os cursos de pós-graduação stricto sensu na modalidade a distância poderão se estruturar pedagogicamente em níveis de mestrado ou doutorado, acadêmicos ou profissionais (BRASIL, 2018, p. 126).

Avançando um pouco mais para atender as demandas e necessidades da sociedade e da qualificação de profisssionais em serviço, o Ministério da Educação (MEC) lança em 2011 o Programa de Mestrado Profissional para Professores da Educação Básica ProEB que tem como objetivo:

A formação continuada stricto sensu dos professores em exercício na rede
pública de educação básica, em conformidade com a política do Ministério da
Educação - MEC, mediante apoio às instituições de ensino superior (IES) ou
rede de instituições associadas do País, responsáveis pela implantação e
execução de cursos com áreas de concentração e temáticas vinculadas
diretamente à melhoria da Educação Básica (CAPES, 2018).

O apoio da CAPES para esta modalidade de curso ocorre mediante a concessão de bolsas e fomento aos cursos de Mestrado Profissional do ProEB, nas modalidades presencial e a distância, no âmbito do Sistema Universidade Aberta do Brasil (UAB). O ProEB tem como finalidade a melhoria da qualidade do ensino nas escolas da Educação Básica Públicas Brasileiras, à medida que:

Promove a formação continuada de professores das redes públicas de
educação, no nível de pós-graduação stricto sensu, nas áreas da Educação
Básica Brasileira;
Institui uma rede nacional para oferta de programas de mestrados
profissionais promovidos por instituições de ensino superior públicas
brasileiras de notória tradição na área de formação de professores e que sejam
partícipes do Sistema Universidade Aberta do Brasil;
Valoriza as experiências advindas da prática do professor ao mesmo tempo
que colabora, através dos trabalhos realizados, para o desenvolvimento de
materiais e estratégias didáticas que ensejam a melhoria do desempenho de
aprendizagem dos alunos;
Cria uma rede de reflexão sobre a realidade do Ensino Básico Público
Brasileiro apontando perspectivas de mudanças e respostas aos problemas do
cotidiano da escola e da sociedade (BRASIL, 2018).

Os Programas de Mestrado Profissional em Rede de Instituições de Ensino Superior (IES) oferecidos hoje a todos os professores em efetivo exercício, ou seja, atuando em sala de aula, tem sua origem no ProEB. Nesse sentido, as IES têm importante papel na mediação e na relação escola e universidade, pois segundo Mororó (2017), a influência da formação de professores na sua prática escolar depende dos mediadores que poderão proporcionar as possibilidades de ruptura com a forma de pensamento cotidiano, permitindo, assim, a aproximação de seu sentido pessoal com o significado social do trabalho docente.

Certamente que o professor da rede pública tem conhecimento e enfrentamentos para os desafios e problemáticas do cotidiano, contudo, a formação continuada é importante aliada na complementação e atualização da formação básica dos professores da rede pública, para assim colaborar com a reflexão de sua prática nos processos educacionais de aproximação com as necessidades de seus estudantes.

Em conformidade com as políticas públicas do MEC, o ProEB visa melhorar a qualidade do ensino nas escolas da educação pública, promovendo educação continuada, instituindo rede nacional de oferta de programas de pós-graduação no âmbito de mestrado profissional, com isso valorizando as experiências dos professores enquanto colabora para o desenvolvimento de trabalhos e matérias, assim como 
estratégias didáticas que buscam a melhoria do desempenho de aprendizagem dos estudantes.

Outra meta dos mestrados profissionais em rede é também criar reflexão sobre a realidade do Ensino Básico Público Brasileiro, mostrando os desafios e apontando as possibilidades de mudanças e respostas às problemáticas do cotidiano escolar. Como vemos, a meta do programa de mestrado vem ao encontro das metas para educação nacional.

Atualmente o ProEB conta com 12 Programas de Mestrado Profissional em diferentes áreas do conhecimento, entre os quais está o Mestrado Profissional em Educação Física em Rede Nacional (ProEF), o qual apresentamos a seguir.

\section{Histórico do Programa de Mestrado Profissional em Educação Física em REDE NACIONAL - PROEF}

O quadro da Educação Física tem passado por importantes modificações desde as décadas de 1970 e 1980. Segundo Moreira e Nista-Piccolo (2016), passamos de um momento de verdades transmitidas para o momento da reflexão crítica, que gerou um momento de crise, oportunidade de mudanças e novas perspectivas. Com os novos paradigmas, a escola foi diretamente impactada, e a Educação Física desponta como disciplina integradora no processo de ensino-aprendizagem que também contribui na preparação para a inserção social e a formação para cidadania crítica (ALBUQUERQUE; BARDY, 2017).

Nesse sentido, novos saberes, estudos, pesquisas e abordagens foram produzidos em diferentes áreas e vinham colaborar com a educação física escolar. Com isso, um grupo de profissionais entendeu que toda essa produção precisava ser difundida de forma nacional e esses saberes deveriam estar ao alcance dos professores de educação física escolar e dos estudantes da rede pública em todo território nacional, destacando que a realização dos cursos de formação continuada de professores era emergencial.

É fato que os cursos de formação continuada não são novidades, os programas lato sensu e stricto sensu existentes realizam um ótimo trabalho e trazem a contribuição para os professores e para as respectivas áreas do conhecimento. Contudo, um Programa de Mestrado Profissional em Rede Nacional, tratando de forma coletiva e colaborativa os problemas da escola junto com seus protagonistas não existia, e seria grande oportunidade para a educação, já que a proposta daria voz ativa ao professor que está no chão da escola.

Com isso, a jornada do ProEF inicia-se em 2012 com a proposta construída por um grupo de professores que idealizava um programa de especialização em rede para os professores de educação física do Brasil. Era um grande projeto à época, envolvia diversos setores e intuições públicas e exigia recursos financeiros e políticas públicas, que naquele momento gerou atrasos e muitos envolvidos aposentaram ou desvincularam-se do grupo que elaborou o projeto por conta dos rompimentos de tratativas iniciais.

Conforme aponta Oliveira (2019), em seu texto buscou retratar e preservar a história inicial do ProEF. O autor cita que:

O convite para a escrita desse prefácio muito me alegra, pois sinto como um reconhecimento pelo trabalho que demos início no ano de 2012. Nesse ano, havíamos idealizado a oferta de um curso de especialização (lato sensu) para a comunidade brasileira da Educação Física, com financiamento do então Ministério do Esporte Coordenação de Aperfeiçoamento de Pessoal de Nível Superior (Capes) (essa Coordenação ainda em estudos e de difícil 


\begin{abstract}
negociação, mas inclinada a nos apoiar). Em 2013, a Professora Suraya Cristina Darido integrou nossa equipe de consultores e, imediatamente, se integrou à proposta e também da situação das tratativas até então adotadas por mim e pela Professora Gianna Lepre Perim, na época Diretora da Secretaria Nacional de Esporte Educacional (SNEED), grande incentivadora e apoiadora da ideia. Aqui vale o registro que sem seu apoio e do então Secretário de Esporte Educacional, Júlio Filgueira, não teríamos conseguido avançar com a proposta. Com a chegada da Professora Darido e do suporte direto da Universidade Estadual Paulista (Unesp), fortalecemos as nossas ações com a Capes em relação à oferta da proposta inicial da especialização. Neste momento, a Capes já estava mais propensa a concentrar seus apoios a programas de pós-graduação em nível stricto sensu (mestrado e doutorado), no caso, mestrado profissional. Confesso que a ideia me assustava um pouco, mas a Professora Darido se animou bastante, encampou a ideia, nos motivou, e, a partir daí, começamos a nova empreita: a elaboração do Mestrado Profissional em Educação Física. Inicialmente nos baseamos em outros projetos que estavam em andamento pela Capes como o PROFMAT, PROFQUI, PROFLETRAS e outros (OLIVEIRA, 2019, p. 10).
\end{abstract}

Muitos desafios permearam a trajetória do ProEF, com o processo seletivo realizado nas IES, em 2016, 181 candidatos aguardavam ansiosamente pela chamada definitiva. Entretanto, as políticas públicas são conturbadas e o processo acabou sendo aprovado, contudo, sem o atendimento ao pacote financeiro esperado, comprometendo em demasia o idealizado e acordado entre as instituições. Isso gerou atrasos, desistências naturais, pois com os cortes, tempo para a aprovação e tramitação geral, muitos dos envolvidos assumiram outras responsabilidades, destaca Oliveira (2019). Assim,

O projeto acabou hibernando um pouco e depois de algum tempo (2018) as professoras Denise Ivana de Paula Albuquerque e Maria Candida Soares DelMasso, da Unesp de Presidente Prudente, corajosamente assumiram e deram continuidade ao processo. Preocupei-me em registrar um pouco das memórias desse processo para que possamos reconhecer o empenho dado por vários atores em diferentes momentos, pois se hoje temos o prazer de ter esse programa, muito se deve aos protagonistas iniciais e, em especial ao papel dessas duas professoras, Denise e Cândida, que deram continuidade ao processo e à efetivação da proposta, mesmo com todos os percalços decorrentes dos cortes e desistências ocorridas (OLIVEIRA, 2019, p. 11).

Assim, conforme mencionado, a proposta é retomada, analisada e elaboradas tratativas para que o ProEF efetivamente tivesse início em 2018, atendendo aos 181 professores aprovados e que participaram da Prova Nacional de Ingresso no programa.

Foram árduos dias e longas reuniões junto às equipes da Unesp para a resolução de questões acadêmico-administrativas e financeiras, assim como reuniões com os docentes das IES Associadas com o intuito de posicioná-los quanto ao atual momento e o que a Unesp desejava para dar início oficialmente às atividades no dia 02 de abril de 2018, conforme solicitação do Pró-Reitor de Pós-Graduação à época, Professor João Lima.

\title{
A realização do ProEF
}

O ProEF iniciou suas atividades com a missão de contribuir para uma qualificação e formação relevante do ensino da Educação Física na escola básica e busca oferecer um curso de formação, na área de concentração da Educação Física Escolar, visando contemplar as necessidades advindas tanto do trabalho cotidiano dos professores, 
quanto das suas próprias necessidades de desenvolvimento e valorização profissional, e, ainda, articular e produzir novos conhecimentos para a área, além de atender demandas sociais e profissionais.

O ProEF representa as propostas pedagógicas que possam inaugurar modos inovadores de legitimar a Educação Física no contexto escolar. A perspectiva de formação está alicerçada em um planejamento adequado, o que significa, em sintonia com as expectativas mais amplas e contemporâneas da educação escolar, bem como uma organização curricular capaz de integrar objetivos da Área de Linguagens e específicos da Educação Física.

De forma inovadora, o ProEF é um curso no modelo híbrido, que oferece atividades na modalidade de Educação a Distância (EaD), via plataforma Moodle e atividades presenciais nas IES Associadas, com oferta nacional, realizado por uma rede de IES no contexto da UAB, sendo coordenado pela Universidade Estadual Paulista "Júlio de Mesquita Filho" (UNESP), junto à Faculdade de Ciências e Tecnologia, câmpus de Presidente Prudente, unidade sede, juntamente com a Faculdade de Ciências do câmpus de Bauru e Instituto de Biociências do câmpus de Rio Claro.

O programa agrega conjunto com 11 IES denominadas Instituições Associadas, sendo elas: Universidade Federal de Mato Grosso (UFMT), Escola Superior de Educação Física da Universidade de Pernambuco (UPE), Universidade Federal de Goiás (UFG), Universidade Federal de São Carlos (UFSCar), Universidade Estadual de Maringá (UEM), Universidade Federal de Rio Grande do Norte (UFRN), Universidade de Brasília (UnB), Universidade Federal do Espírito Santo (UFES), Universidade Federal de Minas Gerais (UFMG), Universidade Regional do Noroeste do Estado do Rio Grande (Unijuí) e Universidade Estadual Paulista "Júlio de Mesquita Filho" (UNESP) - câmpus de Presidente Prudente, Bauru, Rio Claro e estudantes do Rio de Janeiro $^{4}$, conforme apresentando na Figura 1.

Figura 1: Mapa com as 11 instituições associadas ao ProEF.

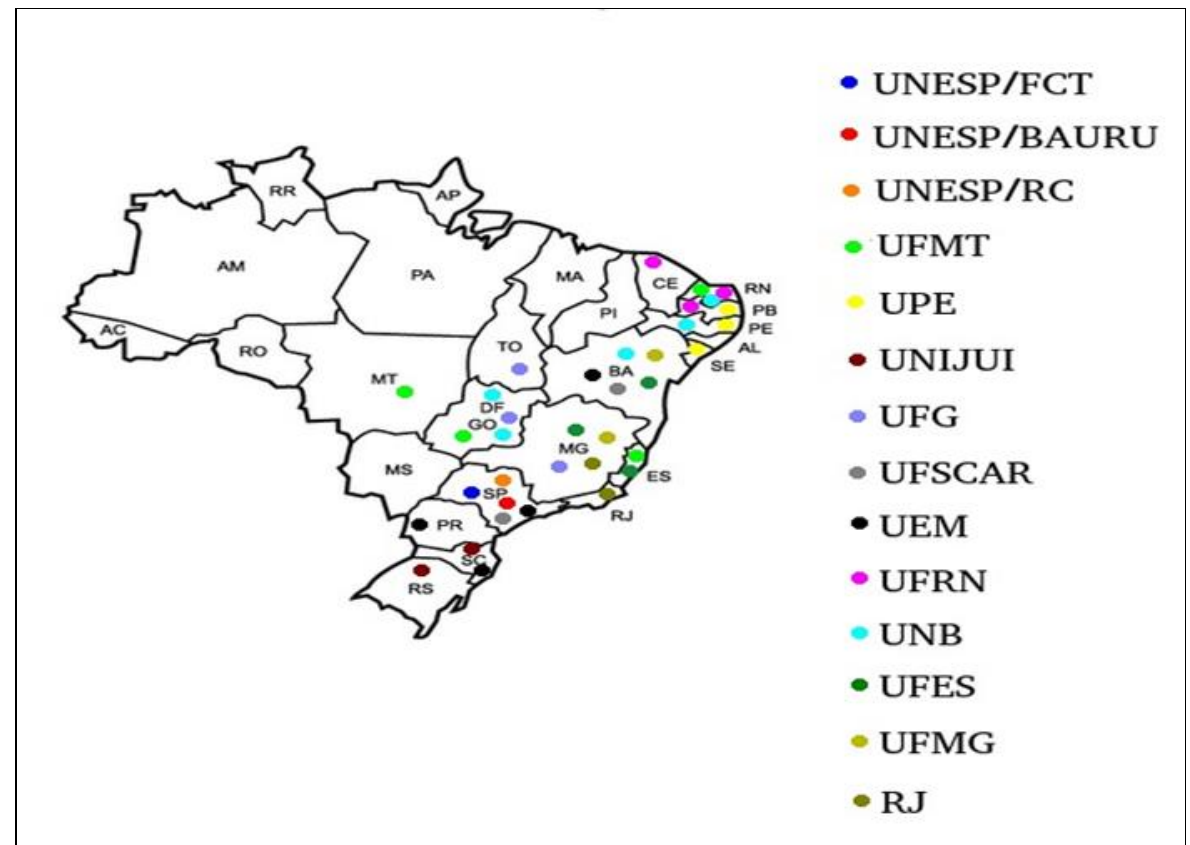

Fonte: Elaborada pelas autoras.

\footnotetext{
${ }^{4}$ Os estudantes do RJ estavam matriculados na UNESP/FCT/Presidente Prudente.
} 
O programa do ProEF reúne pesquisadores experientes nas especialidades requeridas na área de concentração e, claramente, comprometidos com a formação continuada em serviço e em exercício de professores para a área da Educação Física na Educação Básica. Já que a formação continuada é compreendida no ProEF como instrumento de profissionalização essencial para proporcionar aos mestrandos espaços sistemáticos de reflexão conjunta e de investigação, no contexto escolar, acerca das questões enfrentadas pelo coletivo da instituição (Figura 2).

Figura 2: Docentes credenciados no ProEF.

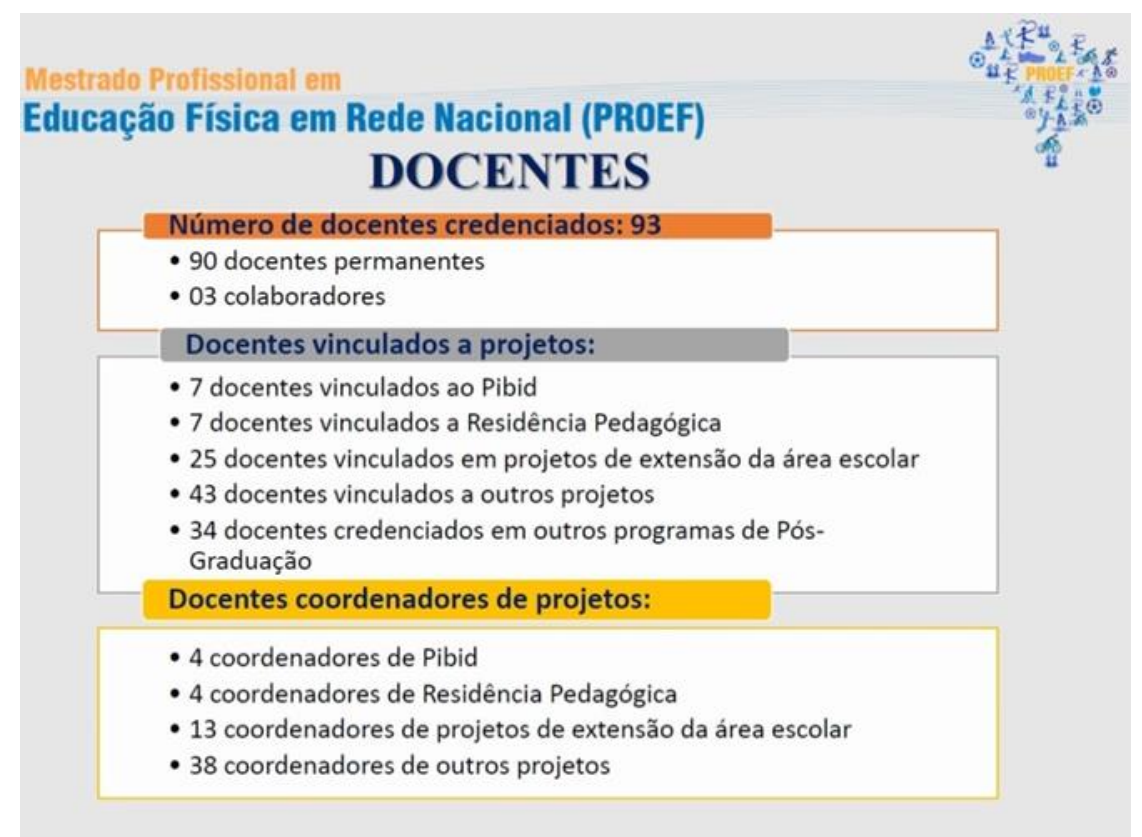

Fonte: Elaborada pelas autoras.

Para início das atividades, o corpo docente do ProEF foi constituído por docentes permanentes e colaboradores, conforme mostrado na Figura 2, credenciados junto às IES Associadas. Cada IES elegeu entre seus docentes o coordenador de Colegiado de Curso, profissional esse que comporia o Conselho Gestor junto dos demais coordenadores de cada uma das IES Associadas e da Coordenação Nacional.

O corpo discente da $1^{\text {a }}$ Turma do ProEF, que ocorreu no período de 2018 a 2020, foi constituído por 176 professores de todas as gerações de egressos de Cursos de Graduação em Educação Física, docentes das redes públicas estaduais ou municipais. Conforme apresentando na Figura 2, os Núcleos do ProEF foram distribuídos entre quatro regiões do país, sendo dois Núcleos (Polos) na região Nordeste congregando a UPE e UFRN; três Núcleos (Polos) na região Centro-Oeste congregando a UFMT, UFG e UnB; seis Núcleos (Polos) na região Sudeste, congregando a UNESP com três Núcleos sendo na FCT/Presidente Prudente, FC/Bauru e IB/Rio Claro, UFSCar, UFES e UFMG e dois Núcleos (Polos) na região Sul, congregando a UNIJUI e UEM. Aspecto importante, alvo de reflexões, é a não existência de Núcleos na região Norte com o registro de inúmeras solicitações para que possamos expandir o ProEF naquela região onde há grande demanda de profissionais que buscam qualificação no âmbito de estudos pós-graduados. 
Figura 3: Mapa dos Polos/IES.

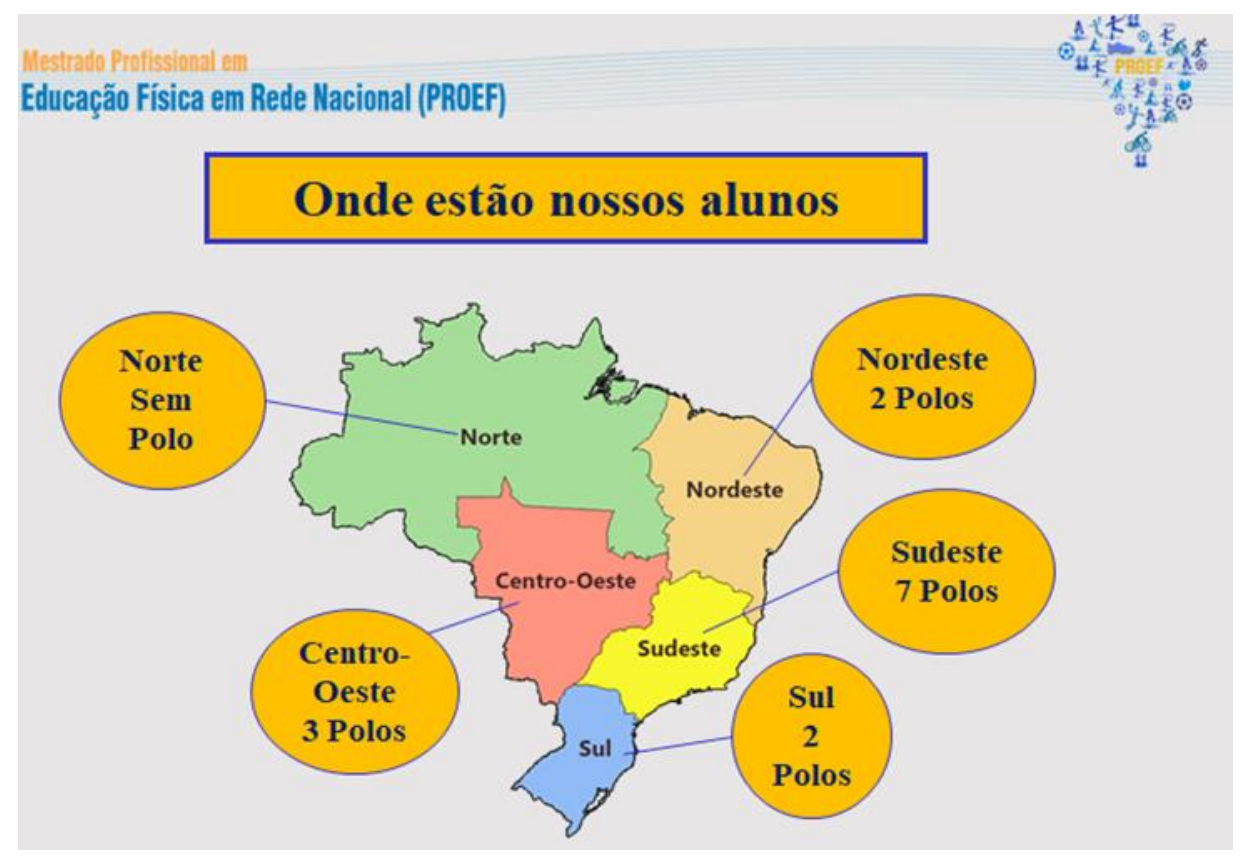

Fonte: Elaborada pelas autoras.

O corpo discente do ProEF caracteriza-se por professores que atuam no ensino da Educação Física em diferentes etapas da escolarização da Educação Básica, em busca de aportes técnico-científicos para melhor proceder às suas práticas profissionais. Face às necessidades que se impõem para a efetivação dos componentes teóricos no contexto escolar, com demandas de qualificação específica, o ProEF se compõe de professores interessados por apropriar-se de pedagogia suficiente, adequada e inovadora no contexto de atualidade da escola brasileira.

Para que o programa tivesse concepção em rede, como eixo norteador da proposta, foram aprovadas Instruções Normativas que estabelecem as diretrizes para as ações nas IES Associadas. Importante instrumento para a regulamentação foi o Regimento Geral do ProEF ${ }^{5}$, após ser revisto e atualizado, a partir da concordância dos respectivos Colegiados de Curso das IES e análise das respectivas instâncias universitárias as quais cada um dos Núcleos estava subordinado. Considerando a característica Interunidades e Interinstitucional do ProEF, as IES Associadas foram orientadas a construir regulamento próprio, seguindo os preceitos dos regimentos de suas pró-reitorias de pós-graduação, considerando que cada Núcleo tem particularidades que deveriam ser respeitadas.

Aspecto fundamental que cabe ressaltar se refere ao Trabalho de Conclusão de Curso do ProEF. Como exigência aos Programas de Pós-Graduação Stricto Sensu, para o Curso de Mestrado acadêmico ou profissional, o discente deve apresentar e defender uma dissertação sobre a temática da área do curso. No caso específico do ProEF, entende-se por Trabalho de Conclusão de Curso, conforme especificado na Instrução Normativa no 10/2019 (CAPES, 2019):

\footnotetext{
${ }^{5}$ A versão atual do Regimento Geral do ProEF encontra-se disponível no sítio do Programa no endereço: https://www.fct.unesp.br/\#!/pos-graduacao/-educacao-fisica/regulamento-normas/
} 
Artigo $1^{\circ}$ - O Trabalho de Conclusão de Curso - TCC, deverá descrever em detalhes o planejamento, o desenvolvimento e os resultados de uma pesquisa e/ou intervenção com implicação no campo profissional da Educação Física no contexto escolar. Deverá estar vinculado em uma das três linhas do programa escolhida pelo aluno no ato da matrícula.

$\S 1^{\circ} \mathrm{O}$ TCC deverá ser apresentado em um texto dissertativo ou relatório científico que precede o produto nos seguintes formatos:

a) projeto curricular para uma etapa e/ou escola da Educação Básica;

b) unidade didática para o ensino de temas e/ou conteúdos específicos da Educação Física Escolar;

c) estratégias de intervenção em problemáticas específicas da Educação Física Escolar;

d) produção de material curricular e de produtos tecnológicos;

e) elaboração de procedimentos, instrumentos de avaliação em Educação Física Escolar;

f) desenvolvimento de aplicativos e de softwares;

g) produção de programas de mídia;

h) produção de materiais didáticos e instrucionais;

i) projetos de inovações tecnológicas (CAPES, 2019, p. 1).

Como descrito na citada portaria do ProEF, o Produto Educacional é o grande avanço na proposta do programa, tendo em vista a perspectiva da concretização da teoria à prática, considerado importante recurso para os professores, que poderão se valer desses materiais para orientar suas práticas pedagógicas, impactando o contexto no qual atuam.

Assim, quando questionamos no início do texto o que se pretende produzir e publicar? Qual a novidade? Para quem? Onde será utilizado? a resposta é dada mediante os inúmeros textos e produtos educacionais produzidos. Percorridos dois anos, contando com 170 mestrandos regulares no programa, a primeira turma encerra com $169^{6}$ defesas realizadas, gerando textos e produtos educacionais disponíveis no Repositório Institucional do ProEF ${ }^{7}$ que agregará todas as IES Associadas. Os créditos das ações do programa devem ser compartilhados com os coordenadores dos Núcleos, que de forma colaborativa junto à Coordenação Nacional, mobilizaram esforços para que o ProEF se efetivasse como um programa de notória qualidade, instituindo, assim, novo momento na Educação Física Escolar, implantando modos inovadores de legitimar essa disciplina no contexto escolar.

\section{DESAFIOS FUTUROS}

Diante das transformações no mundo, que alcançam os mais diversos segmentos, novos temas passam a fazer parte dos debates que se instauram em setores responsáveis pelo desenvolvimento sustentável da sociedade.

Nesse sentido, as Instituições Públicas de Ensino têm o compromisso de acompanhar o avanço dos aspectos que influenciam as ações educacionais. Ao concebermos as mudanças, nas quais o conhecimento e a informação estão disponíveis em nuvens e podem ser acessados a qualquer tempo, em qualquer espaço, é essencial organizar ações que possam garantir a eficácia e a qualidade da educação.

É nesse cenário que o ProEF se insere e representa as propostas pedagógicas que possam implantar práticas inovadoras da Educação Física no contexto escolar.

\footnotetext{
${ }^{6}$ Uma de nossas mestrandas encontra-se em licença maternidade.

7 Em construção quando da finalização deste artigo. O Repositório Institucional do ProEF será disponibilizado na página do programa: https://www.fct.unesp.br/\#!/pos-graduacao/-educacao-fisica/
} 
O ProEF inaugura nova etapa no contexto histórico da Educação Física brasileira ao propor modelo de formação pautado nos princípios da ação-reflexão-ação ao nos referirmos a um programa de mestrado profissional, alicerçado em sólida formação em Educação Física, que contemple as necessidades advindas tanto do trabalho cotidiano dos professores no espaço da escola, quanto das suas necessidades amplas de desenvolvimento e valorização profissional.

A proposta que se coloca como desafio futuro é fortalecer o professor no sentido do enfrentamento dos desafios postos pelo seu exercício profissional. Para tanto, as estratégias empreendidas têm como propósito articular as atividades acadêmicas no sentido de contribuir para a transformação do contexto escolar em diferentes dimensões, demonstrando a importância dos trabalhos a serem desenvolvidos pelos mestrandos do programa, de modo que possam provocar:

- Impacto Tecnológico/econômico que contribuirão para o desenvolvimento do contexto no qual a escola está inserida e os desdobramentos para as famílias e para a comunidade local; Impacto educacional: contribuição para a melhoria do ensino na educação básica, com o desenvolvimento de propostas inovadoras de ensino, metodologias ativas e projetos que sejam efetivos para a transformação de conceitos, atitudes e procedimentos;

- Impacto social: formação de profissionais qualificados para atuação em diversos segmentos da gestão pública e/ou da sociedade; e

- Impacto cultural: formação de profissionais qualificados que possam contribuir para a transformação cultural relacionada à área.

Destacamos que alguns outros dispositivos de acompanhamento, monitoramento e controle deverão ser adotados como forma de superar as dificuldades esperadas. Assim, ao definirmos algumas premissas com foco no futuro, é possível desenhar um cenário prospectivo do programa estabelecendo alguns elementos para serem implementados:

- Autossustentabilidade do programa: estabelecer Convênios e Parcerias;

- Qualificação Docente para a Era Digital: estabelecer uma cultura digital para promover formações para apropriação dos recursos tecnológicos e inovações pedagógicas;

- Valorização da modalidade do Programa: possibilitar a visibilidade do programa em criar um conceito de Rede e, assim, promover e articular ações que envolvam as diferentes IES Associadas;

- Promoção de eventos que levem à compreensão dos mestrandos sobre o comprometimento com o programa durante e após a conclusão;

- Estabelecer parcerias com cursos de graduação, programas e fundações para atuação dos mestrandos e dos futuros egressos;

- Expansão para credenciamento de novas IES respondendo à demanda de procura; e

- Critérios de Avaliação: contribuir para a criação de critérios condizentes com as características específicas do Mestrado Profissional.

Esse conjunto de ações visa a tomada de decisões essenciais para o programa e, assim, preparar os professores, mestrandos do programa, para que possam estar preparados para as constantes mudanças de modo contínuo e sistematizado em seus contextos.

As transformações históricas e culturais têm impactado significativamente o contexto social e educacional e isso se deve ao estabelecimento de nova Socialização 
Cultural, na qual os indivíduos vivenciam, globalmente, diferentes ritmos, devido a seus múltiplos contextos de espaço-tempo. A comunicação em rede possibilita a interação na qual as distâncias geográficas são superadas por meios digitais e virtuais, possibilitando o contato remoto, ou seja, em tempo real, mediado pelas diferentes tecnologias.

Nesse sentido, a Educação e a Escola atuais devem corresponder às expectativas do tempo presente e do futuro, com visão que englobe uma perspectiva do país, e também outra de nível internacional, pois as relações oriundas na sociedade devem garantir a perpetuidade das instituições para que possam cumprir suas missões e, até mesmo para sobreviverem à modernização. Nesse sentido o ProEF tem o compromisso de contribuir para um processo de formação que possa garantir novas formas de conceber, aplicar e repensar os saberes essenciais para a sociedade em constante evolução.

\section{REFERÊNCIAS}

ALBUQUERQUE, D. I. P.; BARDY, L. R. A importância do trabalho colaborativo na educação física escolar. In: ALBUQUERQUE, D. I. P. (org.). Uma escola para todos: reflexões e práticas a partir da educação física. Jundiaí: Paco Editorial, 2017. p. 153-169.

BRASIL. Ministério da Educação. Portaria no 275, de 18 de dezembro de 2018. Dispõe sobre os programas de pós-graduação stricto sensu na modalidade a distância. Brasília, DF: MEC, 2018. Disponível em: https://pesquisa.in.gov.br/imprensa/jsp/visualiza/index.jsp?data=20/12/2018\&jornal=515\&pagina=126. Acesso em: 21 jan. 2021.

BRASIL. Ministério da Educação. Portaria No 389, de 23 de março de 2017. Dispõe sobre o mestrado e doutorado profissional no âmbito da pós-graduação stricto sensu. Brasília, DF: MEC, 2017. Disponível em: https://www.gov.br/capes/pt-br/centrais-de-conteudo/24032017-portaria-no-389-de-23-de-marco-de2017-pdf. Acesso em: 21 jan. 2021.

BRASIL. Ministério da Educação. Portaria Normativa $\mathbf{N}^{\mathbf{0}}$ 07, de 22 de junho de 2009. Dispõe sobre o mestrado profissional no âmbito da Fundação Coordenação de Aperfeiçoamento de Pessoal de Nível Superior - CAPES. Brasília, DF: MEC, 2009a. Disponível em https://www.unifesp.br/campus/sao/meparem/images/docs/Portaria_Normativa_N_07_de_22_de_junho_d e_2009.pdf. Acesso em: 21 jan. 2021.

BRASIL. Ministério da Educação. Portaria Normativa No 17, de 28 de dezembro de 2009. Dispõe sobre o mestrado profissional no âmbito da Fundação Coordenação de Aperfeiçoamento de Pessoal de Nível Superior - CAPES. Brasília, DF: MEC, 2009b. Disponível em: https://www.gov.br/capes/ptbr/centrais-de-conteudo/portarianormativa-17mp-pdf/@@download/file/portarianormativa_17mp.pdf.

Acesso em: 21 jan. 2021.

BRASIL. Ministério da Educação. Nova portaria corrige normas sobre o mestrado profissional. Brasília, DF: MEC, 2009c. Disponível em: http://portal.mec.gov.br/busca-geral/217-noticias/1207656570/14851nova-portaria-corrige-normas-sobre-mestrado-profissional. Acesso em 21 jan. 2021.

BRASIL. Ministério da Educação. Fundação Coordenação de Aperfeiçoamento de Pessoal de Nível Superior [CAPES]. Portaria No 47, de 17 de outubro de 1995. Brasília, DF: Capes, 1995. Disponível em: http://ojs.rbpg.capes.gov.br/index.php/rbpg/article/view/87/83. Acesso em: 21 jan. 2021.

COORDENAÇÃO DE APERFEIÇOAMENTO DE PESSOAL DE NÍVEL SUPERIOR [CAPES]. Universidade Estadual Paulista [Unesp]. Programa de Mestrado Profissional em Educação Física em Rede Nacional [ProEF]. Instrução Normativa $\mathbf{N}^{\mathbf{0}} \mathbf{1 0}$, de 11 de dezembro de 2019. Estabelece critérios para o TRABALHO DE CONCLUSÃO DE CURSO (TCC) junto ao Programa de Mestrado Profissional em Educação Física em Rede Nacional - ProEF. São Paulo: Unesp, 2019. Disponível em: https://www.fct.unesp.br/\#!/pos-graduacao/-educacao-fisica/regulamento-normas/. Acesso em: 21 jan. 2021. 
COORDENAÇÃO DE APERFEIÇOAMENTO DE PESSOAL DE NÍVEL SUPERIOR [CAPES]. Programa de Mestrado Profissional para Professores da Educação Básica - ProEB. Brasília, DF: UAB/Capes, 2018. Disponível em: https://uab.capes.gov.br/educacao-a-distancia/proeb. Acesso em: 21 jan. 2021.

MOREIRA, W. W.; NISTA-PICCOLO, V. L. (org.). Educação física e esporte no século XXI. Campinas: Papirus, 2016.

MORORÓ, L. P. A influência da formação continuada na prática docente. Educação \& Formação, v. 2, n. 1, p. 36-51, jan. 2017. Disponível em: https://revistas.uece.br/index.php/redufor/article/view/122/105. Acesso em: 21 jan. 2021.

OLIVEIRA, A. A. B. Prefácio. In: ALBUQUERQUE, D. I. P.; DEL-MASSO, M. C. S. Desafios da Educação Física Escolar: temáticas da formação em serviço do ProEF. São Paulo: Cultura Acadêmica, 2019. p. 10-13.

SANTOS, G. B.; HORTALE, V. A.; AROUCA, R. A Pós-Graduação Brasileira e o Mestrado Profissional. In: SANTOS, G. B.; HORTALE, V. A.; AROUCA, R. Mestrado Profissional em Saúde Pública: caminhos e identidade. Rio de Janeiro: Fiocruz, 2012. p. 27-41.

SCHÖN, D. A. Educando o profissional reflexivo: um novo design para o ensino e a aprendizagem. Porto Alegre: Artmed, 2000.

WATERS, L. Inimigos da esperança: publicar, perecer e o eclipse da erudição. São Paulo: Unesp, 2006.

Recebido em: 23 jan. 2021.

Aprovado em: 13 abr. 2021. 